\title{
ORGANIZATIONAL PATH DEPENDENCE: OPENING THE BLACK BOX
}

\author{
JÖRG SYDOW \\ GEORG SCHREYÖGG \\ Freie Universitöt Berlin \\ JOCHEN KOCH \\ European University Viadrina
}

\begin{abstract}
To enable a better understanding of the underlying logic of path dependence, we set forth a theoretical framework explaining how organizations become path dependent. At its core are the dynamics of self-reinforcing mechanisms, which are likely to lead an organization into a lock-in. By drawing on studies of technological paths, we conceptualize the emergent process of path dependence along three distinct stages. We also use the model to explore breakouts from organizational path dependence and discuss implications for managing and researching organizational paths.
\end{abstract}

The discourse on organizational innovation and change has become more complex. On the one hand, there is an ever-increasing demand for more flexible or even fluid "new" organizational forms. On the other hand, studies stressing organizational inertia and the historical imprinting of decision making ("history matters") have come to the fore in management and organization theory. There seems to be a broadly shared feeling that we need to understand better how organizations can lose their flexibility and become inert or even locked in. Among the most referred to conceptions, path dependence has recently gained prominence. Many contributions refer to path dependence to illuminate organizational rigidities, stickiness, or inflexibility. ${ }^{1}$ But what is path dependence supposed to

\footnotetext{
We thank the four anonymous reviewers for their helpful comments, and we particularly thank former associate editor Pamela Tolbert for her thoughtful advice. Earlier versions of the manuscript profited significantly from discussions in the subgroup on path dependence and creation at the 21st EGOS Colloquium in Berlin, 2005, and at the annual meeting of the Academy of Management in Atlanta, 2006. We are grateful to the German Research Foundation (DFG) for funding the doctoral program Research on Organizational Paths at Freie Universitöt Berlin and to its members for providing a stimulating environment for the research.

${ }^{1}$ A quick search for references to path dependence in papers published between 1995 and 2008 in three leading scholarly journals (Administrative Science Quarterly, Organization Science, and Organization Studies) showed that more than eighty papers referred to this concept. That is about 4.3 percent of the articles published in those journals over this time span-an average of 0.3 papers per issue.
}

mean exactly? In organization research the term is used mostly as a broad label indicating all kinds of imprinting effects of the past on organizational behavior (e.g., recently, Beckman \& Burton, 2008). A closer examination quickly reveals that the predominant usage is more metaphorical than theoretical in nature. A clear specification is usually missing. This means, at the same time, that no indicators are available that allow for examining whether or not the organizational phenomena in question are actually path dependent. If we want "path dependence" to provide more than a synonym for persistence, then we need a theoretical framework clarifying the notion and helping us better understand the conditions and dynamics under which organizations become path dependent. By addressing this gap in management and organization research, we aim to offer a framework designed to explain organizational path dependence.

The endeavor to explain organizational rigidities and structural inertia is not new in management and organization research. Over the years scholars have accumulated ample evidence on change-inhibiting forces. Various studies have highlighted cases of persistence and irreversibility of organizational strategies, designs, and competences by drawing, for instance, on awkward routines, groupthink, or fixed cognitive maps (e.g., Beckman \& Burton, 2008; Burgelman, 2002; Collinson \& Wilson, 2006; Gilbert, 2005; Hannan \& Freeman, 1984; Helfat, 1994; Huff \& Huff, 2000; Stimpert, Wasserman, \&

Copyright of the Academy of Management, all rights reserved. Contents may not be copied, emailed, posted to a listserv, or otherwise transmitted without the copyrigh holder's express written permission. Users may print, download, or email articles for individual use only. 
Jayaran, 1998; Tripsas \& Gavetti, 2000). Path dependence, however, is supposed to mean more than the mere existence of timeworn routines, cognitive rigidities, or structural inertia. It is, first of all, a process. Its distinguishing features need elaboration.

The starting point of any advanced path dependence thought stresses the importance of past events for future action or, in a more focused way, of foregoing decisions for current and future decision making. Hence, decisions are conceived of as historically conditioned"bygones are rarely bygones" (Teece, Pisano, \& Shuen, 1997: 522). In short, the basic thesis holds that history matters (e.g., Nooteboom, 1997; Sewell, 1996).

This essential insight has certainly advanced the understanding of emerging organizational phenomena and has helped to overcome the ahistorical and unbounded view of rational choice thought. We learn that history can be quite important for explaining strategic choices and organizational failures. While we appreciate this insight, merely focusing on the fact of past dependence (Antonelli, 1999) implies taking a fairly broad view-too broad a theoretical perspective: if we base path dependence explanations on the history matters argument only, the notion is likely to become indistinct. All human activity and organizational processes are imprinted by their history in a way, so we would end up by concluding that all organizational decisions and actions are path dependent. Such a ubiquitous, all-embracing understanding of path dependence would bring us close to a truism. Path dependence relates to more specific constellations; it includes features such as sustained persistency and lock-in, which are definitely not a common characteristic of decision processes. A theory of organizational path dependence therefore needs a more elaborated framework, which takes us beyond the mere insight that past events influence subsequent actions.

To gain a deeper understanding of the organizational patterns considered to be path dependent, along with their underlying causal mechanisms, it is instructive to explore the cases and conceptual suggestions provided by studies on technological paths. Paul David $(1985,1986)$ provides the most prominent example of technological path dependence-the well-known standard of the QWERTY keyboard and its amazing predominance for more than 100 years. This standard has spread around the world and, puzzlingly enough, has never been seriously challenged by all the newly developed, technically more efficient alternatives. David explains this inefficient long-term predominance as being the result of a path-dependent process, which was set up owing to some initial events and advanced mainly through network externalities leading to a technological lock-in early on.

The QWERTY case and similar case studies from technology diffusion, economic history, and evolutionary economics (e.g., Antonelli, 1999; Callon, 1992; Castaldi \& Dosi, 2006; Dosi, 1982; Hughes, 1987) offer intriguing evidence of similar persistence in national and global contexts. Arthur (1989, 1994) was the first to model a formal theory of path dependence and to expose increasing returns as the major process driver. Later on, this thinking was extended to the economics of institutions (North, 1990). However, up to now, studies of path dependence (in this specified sense) neither addressed the persistence of organizations nor explored the logic and dynamics of internal organizational processes leading to a lock-in. We fill this gap by elaborating a theory of organizational path dependence and lock-in. Building on the evidence and insights from research on technological paths, we develop a theoretical framework to gain a better understanding of how organizational path dependence comes into existence. In pursuing this aim, we also integrate insights from institutional economics (North, 1990), as well as from political science (in particular, Mahoney, 2000; Pierson, 2000, 2004; Thelen, 1999), theories of institutionalization (Lawrence, Winn, \& Jennings, 2001; Powell \& DiMaggio, 199l; Tolbert \& Zucker, 1996), and related organization studies (Boeker, 1989; Johnson, 2007; Stinchcombe, 1965). In a subsequent section we will, however, also show where the differences to these organizational approaches can be found.

In essence, we suggest a framework that differentiates three developmental phases of path dependence, starting with (1) singular historical events, (2) which may, under certain conditions, transform themselves into self-reinforcing dynamics, and (3) possibly end up in an organizational lock-in. The three phases are each assumed to be governed by different regimes. The suggested model aims at providing an explanatory framework but also an operational scheme 
for investigating claimed path dependence in and of organizations. Furthermore, we explore whether and how organizational path dependencies and lock-ins can be overcome (unlocked). We conclude by considering implications for research and management.

\section{ADVANCING A DYNAMIC FRAMEWORK OF ORGANIZATIONAL PATH DEPENDENCE}

Valuable insights into the dynamic nature of entrapping or locking processes have already been provided by studies from evolutionary economics and economic history, although these, as already indicated, focus almost exclusively on technological innovation at the field or market level (Arthur, 1989, 1994; David, 1985, 1986; Dosi, 1982, 1997). At the core, these studies identify self-reinforcing processes as drivers that are likely to accumulate in a specific path of action. These inherent self-reinforcing dynamics that eventually lead to an irreversible state of total inflexibility or lock-in (David, 1985) are seen as becoming increasingly systemic forces, beyond the control of the individual actor. In other words, the individual actor becomes entrapped in the system's dynamics.

It is difficult to conceptualize the general logic of this type of entropping process. Arthur (1994; see also Pierson, 2000: 253) has advanced its most explicit characterization. In his view the process of becoming path dependent can be characterized by four general properties:

1. Nonpredictability-there is an indeterminacy of outcome.

2. Nonergodicity-several outcomes are possible (multiple equilibria), and history selects among the possible alternatives.

3. Inflexibility - the actors are entrapped, so a shift to another option is impossible.

4. Inefficiency-actions resulting from the path lock the market into an inferior solution.

These four properties provide a first orientation for differentiating between path-dependent and non-path-dependent processes. However, the properties seem to be somewhat overgeneralized, and they do not actually apply to the whole process of becoming locked into a path. Rather, they appear to cover specific episodes in this process. Take, for instance, nonpredictability; this trait applies only to the beginning of the process, when the outcome is actually unpre- dictable. Later on, as the path is increasingly formed, by implication, the actions become more and more predictable. Having arrived at the lock-in stage, the behavior even becomes fully predictable. The reverse is true for nonergodicity and inflexibility: it is only at the later stages that $a$ path process rigidifies. In the beginning the process is assumed to be flexible. And, similarly, inefficiency becomes a feature of the later stages only; initially, before a path is shaping, the situation is open (unpredictable) and-as Arthur (1994: 116) himself stresses-the choices may well be efficient. It is only at a later stage that a more efficient option may emerge, which actors can no longer choose because they are locked in, thus causing inefficiency.

These brief considerations advise us to differentiate explicitly among different stages in the formation of a path and to specify their structural properties. To elaborate on a theory of organizational path dependence, we therefore suggest subdividing the whole process of evolving path dependence into three stages governed by different causal regimes and constituting different settings for organizational action and decision making.

Phase I-the Preformation Phase-is characterized by a broad scope of action. The effect of a choice of options cannot be predicted (see also Mahoney, 2000: 511). Once a decision is made, this choice may, however, amount to a small event that unintentionally sets off a selfreinforcing process. This moment of entering into the dynamics of a self-reinforcing process can be thought of as a "critical juncture" (Collier \& Collier, 1991), and it indicates the end of the Preformation Phase. Drawing on complexity theory, this transition comes close to "bifurcation" (Kauffman, 1993).

In Phase II-the Formation Phase-a new regime takes the lead: the dynamics of selfreinforcing processes (Arthur, 1994). A dominant action pattern is likely to emerge, which renders the whole process more and more irreversible. By implication, the range of options narrows, and it becomes progressively difficult to reverse the initial choice or the initial pattern of action-that is, a path is evolving. Decision processes in Phase II are, however, still contingent; they are nonergodic (not accidental)-that is, they do not yet fully converge to a fixed-point distribution (David, 1985). 
The transition from Phase II to Phase III-the Lock-in Phase-is characterized by a further constriction, which eventually leads to a lockin-that is, the dominant decision pattern becomes fixed and gains a deterministic character; eventually, the actions are fully bound to a path. One particular choice or action pattern has become the predominant mode, and flexibility has been lost. Even new entrants into this field of action cannot refrain from adopting it. When more efficient alternatives are available, individuals' and organizations' decision processes and established practices continue to reproduce this and only this particular outcome. The occurrence of a lock-in renders a system potentially inefficient, because it loses its capability to adopt better alternatives.

Figure 1 illustrates the process across the three stages. This differentiated framework is intended as a general model of path dependence; its functioning, however, is likely to differ from context to context according to the prevailing conditions, particularly market versus hierarchy. The contextual specifics when applied to an organizational context-the target field of this contribution-will be outlined in subsequent sections.

\section{Preformation Phase}

Phase I can be characterized as an open situation with no significantly restricted scope of action. From a theoretical point of view, the question that arises is how this initial state can be conceptualized in more distinctive terms. The technological path studies-if at all-have conceived of the initial situation as being unrestricted. The search for alternatives starts from scratch, and decisions are unconstrained.

Such framing of the first stage in the rational choice tradition, however, paradoxically ignores the fact that the development of a path is embedded and connected with other developments; it cannot be considered a completely separate process without any imprints from the past. In brief, history matters in the Preformation Phase too. In organizations initial choices and actions are embedded in routines and practices; they reflect the heritage-the rules and the culturemaking up those institutions (e.g., Child, 1997; March, 1994; Tolbert \& Zucker, 1996). Institutions are "carriers of history" (David, 1994), and history cannot be intermittent; it does not matter only occasionally-it always matters! A conceptualization of the activities in the Preformation Phase thus cannot start from scratch; it has to account for institutional imprints.

On the other hand, history in this broad sense is not destiny; we have to draw a clear distinction between historical-institutional influences and imperatives. The notion of path dependence does not refer to a state of determinacy from the beginning; it sheds light on a tapering process that possibly ends in a lock-in. Increasing path dependence implies an initial scope of choice. Otherwise, the theory would lose its very point:

FIGURE 1

The Constitution of an Organizational Path

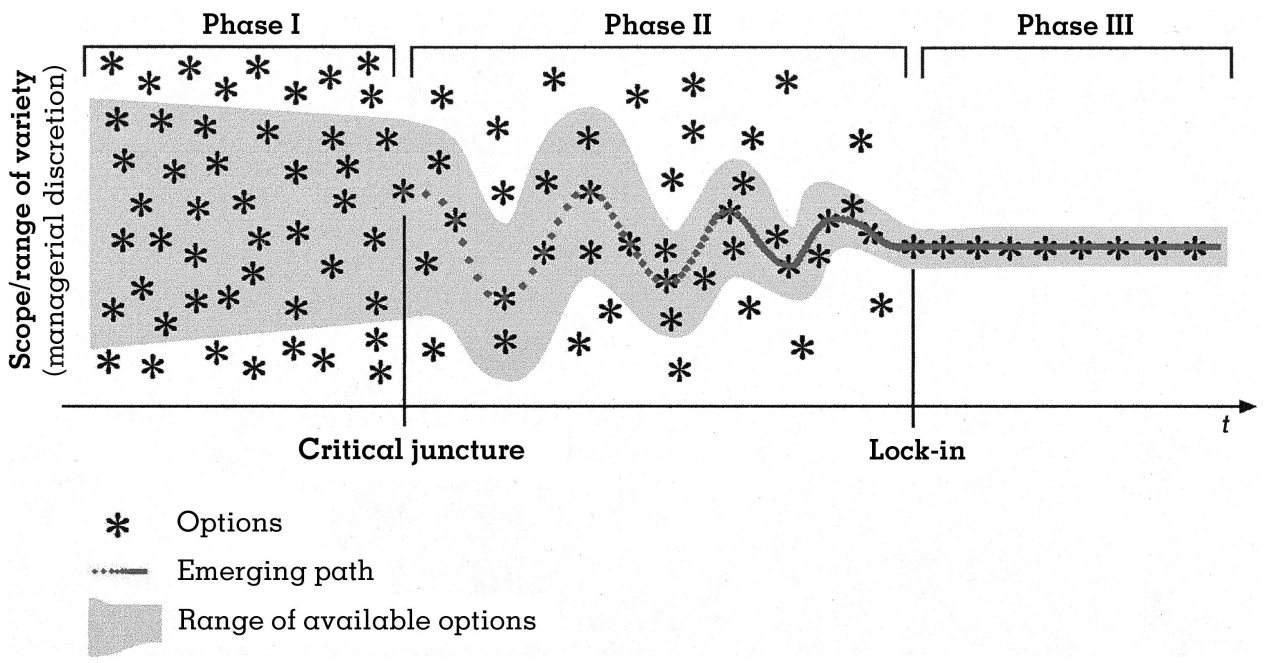


to make tapering processes in organizational reality better understood. Thus, Phase I should build on a historically framed or imprinted contingency and, therefore, neither on the assumption of determinacy nor on that of completely unrestricted choice. The shadow in Phase I in Figure $l$ is intended to indicate this institutional heritage.

A related issue is the triggering of further reactions. The initial choice in a process that becomes path dependent later on is not simply a single event; it is an impetus, a trigger stimulating further actions, which may accumulate in an organizational path. Arthur (1994: 14) characterizes these initial choices as "small events." Drawing on complexity theory (Kauffman, 1993), we conceptualize the triggering as bifurcation: small events may cause unintended, far-reaching consequences-as is the case, for instance, with the well-known butterfly effect. ${ }^{2}$ Because several outcomes initially are possible, the historical sequence of choices becomes decisive in determining the final outcome; the first choice (or action), however, is random (David, 1985).

It is doubtless appealing to conceive of triggers of path dependence as small and random events, but for the purpose of organizational analysis, we need to expand the scope. Since organizations are social systems and not markets or natural entities, triggering events in organizations are likely to prove to be not so innocent, random, or "small" (cf. also Bassanini \& Dosi, 2001). For instance, in the case of the VHS monopoly that has been intensively studied from a path dependence perspective $(\mathrm{Cu}-$ sumano, Mylonadis, \& Rosenbloom, 1992), the triggering event was neither a random nor a small one. Rather, it was Matsushita's initial move to secure content delivery through an agreement with major Hollywood studios that happened to become the crucial step in defeating the technologically superior Sony Beta standard. Similarly, in Cowan's (1990) study of nuclear power plants, initial choices reflected intentions, not randomness. These (and other)

\footnotetext{
${ }^{2}$ Here the flap of a butterfly's wings represents a small random change in the initial condition of the system (atmosphere), which sets in motion a chain of events eventually causing a large-scale change (tornado). Had the small event not occurred, the development of the whole system might have been vastly different (for a more detailed account, see Hilborn, 2004).
}

cases invite a rethinking of the small event framing: path dependence may be triggered by "bigger" events or even strategies as well.

A less randomized modeling of these initial activities thus seems advisable-at least for organizational contexts. It is, however, important to realize that in the nonlinear logic of path dependence, irrespective of whether the initial actions are big or small, they can never be considered causal determinants. A determined process would follow a prescribed course of events right from the beginning, as is the case with linear cause-and-effect laws. Opposed to that, the very point of early path developments is that they are contingent in character. Moreover, their outcomes are unforeseeable consequences of purposeful action (Merton, 1936). The outcome cannot be known unless the process has been formed.

\section{Formation Phase}

Phase II is characterized by the gradual emergence of an organizational path. The scope of action is assumed to narrow increasingly because of the "pull" of the evolving path. An initially unknown regime ${ }^{3}$ happens to take the lead, which favors a particular type of decision or action pattern and reproduces it over a certain period of time. This phase commences with a critical juncture at the passage from Phase I to II. A decision made or an action taken in Phase I amounts to a trigger for the further development of the organization or an organizational subsystem. However, not all cases of competing solutions culminate in path dependence. It is therefore of critical importance to indicate such cases in which path dependence is likely to develop.

Early studies on technological path dependence (Dovid, 1985, 1986) highlighted the central role of self-reinforcing processes for path building. Arthur (1989, 1994) elaborated on these driving forces and specified "increasing returns" as the decisive feature; this builds on the assumption that the decision to reproduce a particular

\footnotetext{
${ }^{3}$ It should be stressed that in Arthur's well-known Polya urn model, the self-reinforcing mechanisms are already set up right from the beginning (Arthur, 1989); the experimenter determines the rules. From our point of view, however, this is owing to the necessities of a formal model rather than a theoretical statement.
} 
option is suggested by a utility calculus. While in no way we exclude this case, it seems too restrictive a starting point for the organizational context (see also critical comments by Crouch \& Farrell, 2004; Eden, 2004; Ortmann, 1995). Focusing on utility-driven behavior only implies a disregard for important insights of organizational studies. Self-reinforcing patterns in organizations have been shown to result from other factors as well, such as emotional reactions (uncertainty avoidance, intergroup revenge, etc.), cognitive biases (selective perception, blind spots, implicit theories, etc.), and even political processes (gaining and maintaining power, reciprocal negotiation). These aspects have to be included in a theory of organizational paths to represent the scope of organizational behavior possibly activating self-reinforcing effects. More precisely, we suggest including different forms of positive feedback cycles based on specific organizational forces.

A related problem of the technological path dependence studies results from their focus on individual decision making. This exclusive focus on individuals does not account for the institutional setting in which organizational positive feedback processes happen to occur. It is the broader organizational context (e.g., hidden assumptions of the organization, organizational culture, status and role system, and institutionalized practices) that informs decision makers and provides the basis, indirectly and inadvertently, for the development of self-reinforcing loops.

On a general level the concept of increasing returns highlights positive feedback processesthat is, the increase of a particular variable leads to a further increase of this very variable. More specifically, the notion of increasing returns indicates self-reinforcing processes with increasing benefits; repetitive pursuits to earn this increasing rent are likely to culminate in a patterned dynamic. Eventually, a dominant solution emerges in terms of recursive action patterns (Giddens, 1984). The flip side of these returns is that the whole process becomes more and more irreversible, particularly in cases of high investments and/or high fixed costs (Ghemawat, 1991). Decision processes in Phase II, however, are still contingent or nonergodic (David, 1985) - that is, while essentially constrained, choices are still possible (the shadow of Phase II in Figure 1 is designed to indicate the still prevalent situation of contingency). One of the subsequent sections elaborates on major self-reinforcing processes in organizations.

\section{Lock-in Phase}

The transition from Phase II to Phase III is characterized by a further restriction of the scope. The focal action pattern is replicated even more, which eventually leads the whole setting into a lock-in. Because of the circumstances, this lock-in may be of a predominantly cognitive, normative, or resource-based nature (Giddens, 1984). Although organizational studies mostly emphasize the role of managerial cognitions or beliefs or resources, organizational lockins are also likely to be combinations of all three dimensions.

In its extreme form the dominant pattern gains a deterministic character, and alternative courses of action are no longer feasible for various reasons: high switching costs, sunk costs, monopoly, and so forth. By implication, further decisions (owing to lack of alternatives, they are actually no longer decisions) are bound to replicate the path. Even newcomers are forced to adopt it. Agents continue to reproduce this and only this particular outcome. This extreme form of lock-in has been found with technological solutions (e.g., the QWERTY keyboord).

Considering organizational paths, however, the context seems to be significantly different, requiring a somewhat modified conception of lock-in. Organizational settings cannot readily be equated with markets and monopoly. Because of their social character, organizational processes are more complex and ambiguous in nature. They are not likely to amount to a state of full determinacy, which excludes any alternative choices. Rather, self-reinforcing dynamics are expected to bring about a preferred action pattern, which then gets deeply embedded in organizational practice and replicated. Hierarchy provides formal authority and legitimate influence on members' behavior; orders can potentially stop inefficient replication. On the other hand, fixed and inflexible behavior is a widely recognized feature in the organizational change literature. It is well known that, from time to time, despite hierarchical control, it is extremely hard to change organizational action patterns (e.g., Beer \& Nohria, 2000; Kaufman, 1995); they are quasi locked in. We should nevertheless re- 
frain from reifying organizational paths and attributing an objective quality to social rigidifying processes. In organizational settings, therefore, we suggest conceptualizing the final stage of a path-dependent process in a less restrictive way-as a predominant social influence, leaving some scope for variation (Pierson, 2000; Thelen, 1999; for illustrative examples see Bruggeman, 2002; Burgelman, in press; Eden, 2004; Hollingsworth, 2006).

In more detail, it seems promising to conceive of the lock-in stage in terms of an underlying core pattern (invisible "deep structure"), with some variation in practicing it (visible activity level). Actors in the final phase do not simply experience the path; rather, as "knowledgeable agents" (Giddens, 1984), they have scope in interpreting the organizational patterns. This individual interpretation of the core (path) is likely to bring about some variation in actual organizational action patterns. While the underlying path structure is fixed, its replicative practice is subject to some variation. In a way, this argument echoes the conception of routines advanced by Feldman and Pentland (2003), stressing, on the one hand, the ostensive side as a fixed, overarching pattern and, on the other hand, the performative side as the actual practicing of a routine involving some variation. In conclusion, for organizational settings it seems more adequate to conceive of the lock-in state not in terms of total rigidity but, rather, as a matter of degree, accounting for variance in the actual practicing of the organizational path. A corridor may best serve to illustrate this reasoning; the shadow in Phase III in Figure 1 is designed to indicate this adaptation. Although highlighting these differentiations, the lock-in phase is nevertheless constitutive for path dependence. If actors were not locked in, one would not call the process path dependent.

Whatever the best conceptualization of organizational lock-ins, the more controversial feature of this stage is efficiency. In David's initial framework (1985) inefficiency was considered a necessary element, because he set out to explain a puzzle: how could an inferior solution like the QWERTY keyboard endure in a market economy? So he started with inefficiency right from the beginning. Subsequent work called this element into question and suggested a modified perspective (Arthur, 1994; Pierson, 2000)—the argument being that path analyses merely ad- dress nonergodic inflexible processes (as opposed to linear ergodic processes). A separate question is whether the state finally reached is efficient or inefficient, and the answer to this question is not considered part of the theory of path dependence. Although we appreciate this argument, from our point of view it misrepresents the very intention of path analyses. The primary interest is not in the formal logic of nonlinear nonergodic processes as such; rather, it is nourished from congealing processes and puzzling persistencies that are likely to hamper present and future scopes of action. In other words, it is at least potential inefficiency that is worrying and makes path dependence a matter of high importance. We therefore advocate including inefficiency in an organizational theory of path dependence.

It is true that a narrowing organizational process and lock-in do not automatically mean immediate inefficiency or losses. Path dependence and efficiency, however, do not refer to a certain point in time; instead, a longer time horizon is covered, necessarily including the alerting risk of becoming dysfunctional. From a strategic, future-oriented point of view, rigidity therefore always means potential inefficiency. If an organization or a significant practice (e.g., combining specific R\&D capabilities with marketing skills) has become locked in, there is inherently the danger of becoming inefficient, either in the face of new, more efficient alternatives or changed internal or external circumstances calling for new solutions. Latent inefficiency becomes manifest when an organization confronted with these change requirements cannot adopt new measures because it is confined to the existing path of action, which binds it to the historical solutions (Leonard-Barton, 1995; Schreyögg \& Kliesch-Eberl, 2007). This dysfunctional flip or rationality shift from initial reinforcing earnings to strong barriers to change and losses should therefore be considered a constitutive element of organizational path analyses.

In any case, calling a lock-in "inefficient" always implies a base of reference-a comparison with another standard. The base of reference can differ; it is not a fact but, rather, depends on the perspective taken (focusing on a group, a department, the whole organization, the field). By implication, discussing the inefficiency of an organizational path always requires the exposure of the base of reference applied. 
To sum up, the proposed theory conceptualizes an organizational path as a tapering social process. Starting (Phase I) with contingency, a critical event (decision, accident, etc.) favors a solution leading unpredictably to a critical juncture. If it triggers a regime of positive, selfreinforcing feedback, this solution progressively gains dominance (Phase II). This pattern is likely to become persistently reproduced and to crowd out alternative solutions to an extent that it gets locked in (Phase III) and is accompanied by immediate or future inefficiency. In short, organizational path dependence can be defined as a rigidified, potentially inefficient action pattern built up by the unintended consequences of former decisions and positive feedback processes.

\section{COMPARING RELATED CONCEPTIONS}

The suggested framework needs discussion and refinement to further clarify the causal logic of path-building processes. In particular, the concrete forms of self-reinforcing organizational dynamics need elaboration. In a first step, however, it seems advisable to sharpen the model's distinguishing features by contrasting it with related conceptions that also highlight the importance of initial conditions and events for organizational development, such as imprinting or escalating commitment.

\section{Imprinting}

The concept of imprinting (Beckman \& Burton, 2008; Boeker, 1989; Johnson, 2007; Stinchcombe, 1965) figures prominently among approaches that seem to address a process very similar to organizational path dependence. Basically, this concept postulates that either initial cognitive schemes, competences, and so forth-of a founding entrepreneur or team, for instance-or specific contextual conditions (organizational structure, postwar depression, internet boom, etc.) at the time of founding imprint organizational processes at later stages and, eventually, amount to a replicated pattern. Although there are doubtless striking similarities that lead many authors to either simply equate imprinting and path dependence or to conceive the former as a specific variant of the latter (e.g.,
Beckman \& Burton, 2008), the process of becoming path dependent is governed by a different logic.

First, the replicated pattern in the imprinting approach is ready-made at the beginning; it is a specific scheme that persists and continues to influence future processes. In contrast, the gestalt of an organizational path is not clear at all in the early stage; it is an unforeseeable product of later processes, which are initially unknown. Path dependence is an offspring of the nature of the process. Second, because of this, a theory of organizational paths-as opposed to the imprinting approach-has to explain the unfolding process of path formation, not only the reproduction of structural properties because of either efficiency or a lack of competition (Stinchcombe, 1965), or the presence of institutionalization processes (Johnson, 2007). Nevertheless, imprints doubtless play an important role in many organizational processes. In path-dependent organizational processes they can, for instance, explain the restrictions in the Preformation Phase.

\section{Escalating Commitment}

Another concept that shares striking similarities with organizational path dependence is escalating commitment (Ross \& Staw, 1993; Staw, 1976). As happens in cases of path dependence, particularly in the inefficient Lock-in Phase, escalating commitment prevents organizational decision makers from changing their course of action, despite continued negative feedback on the outcome. Instead of stopping, the agents replicate the inefficient solution-in particular, the tendency to throw good money after bad (see Guler, 2007)-for various reasons.

There is, however, a major difference between escalating commitment and path dependence explanations. The latter consider a process with a more or less accidental beginning and a longer phase of success; it is only in the final stage that the persistent course of action shifts into inefficiency. In contrast, escalating commitment captures situations where the course of action fails from the very beginning. Since there are no increasing returns or similar enhancing effects, it highlights another problem areanamely, pathological decision behavior based on the dynamics of self-justification and fears of losing face. 


\section{Commitment/Sunk Cost}

There is another related stream of thought highlighting persistence through resource commitments and subsequent exit barriers (Ghemawat, 1991). Early investment is assumed to restrict the future scope of action. This argument comes close to sunk cost. Sunk cost thought, however, has its own ambiguity. As we can learn from microeconomics, sunk costs are only a psychological outcome of imagination; from a rational choice point of view (e.g., Pindyck \& Rubinfeld, 2005), they are irrelevant. Organizations can ignore them because they are, in fact, not relevant for their future decisions. If there are new and better projects, the capital market will provide fresh money to overcome the old structure.

Apart from this idealized counterargument (it takes an efficient capital market for granted), the simple fact of past investments (in terms of sunk costs) cannot be equated with path dependence, since, in consequence, all investments would bring about path dependence (for a more sophisticated argument in this direction, see Arrow, 2004). This refers back to our initial statement that we should refrain from conceptualizations that end up considering all past dependence as path dependence.

In a similar vein, Pierson (2000) raises the issue of whether increasing returns or other selfreinforcing processes should be made a necessary element of path theory. Among others, he highlights pure complementarities as being likely to bring about persistency. From our point of view, this argument refers to a different type of rigidity. Pure complementarities without selfreinforcing processes characterize a stable situation of fitting resources, but not a process that eventually leads to a lock-in. If there is no escalating self-reinforcing process, switching to new and better opportunities may be difficult but not increasingly impossible.

\section{Structural Inertia}

There is another well-known argument on organizational persistency that has been advanced by population ecology (Gresov, Haveman, \& Olivia, 1993; Hannan \& Freeman, 1984; Hannan, Plos, \& Carroll, 2004; Ruef, 1997). In this perspective structural inertia-the hyperstability of organizational arrangements in spite of environmental change-is a universal organizational feature that develops in the course of structuring the organization. Routinizing and institutionalizing organizational activities are seen as imperative in order to guarantee stakeholders reliability, accountability, and, finally, survival in competitive environments. Inertia is considered a precondition for effective organizational acting but, paradoxically enough, eventually threatens the organization's survival, because it is likely to bring about a mismatch with changing environmental conditions.

Again, the phenomenon is somewhat similar to organizational path dependence, but the focused process and its explanations are clearly at variance. Inertia occurs via the intended establishment of reliable organizational structures; there are no structural dynamics. It is a universal requirement that all organizations have to fulfill. And all organizations, especially when growing and aging, are also expected to become hyperstable, with difficulties in meeting new environmental challenges. Opposed to that, the suggested framework of path dependence does not apply to all organizations (it highlights special cases only) and requires an avalanchelike process to bring about a lock-in. The focus is on explaining the process and its various stages. ${ }^{4}$

\section{Reactive Sequences}

While subscribing to the suggested type of path-building process, Mahoney (2000) develops a second type-namely, efficient or inefficient trajectories built up by reactive sequences. This process is characterized by a chain of modular events governed by singular cause-and-effect relationships. A focal event, B, is assumed to be the effect of a prior event, $A$, and at the same

\footnotetext{
${ }^{4}$ Carroll and Harrison (1994) point to the importance of positive feedback in the ecological model, but only with respect to density dependence; a more general consideration of the importance of self-reinforcing processes does not seem to be intended. Other evolutionary and, more recently, coevolutionary theorists make explicit use of the notion of path dependence and tend to prefer it to other concepts (e.g., Helfat, 1994; Nelson \& Winter, 1982; Volberda \& Lewin, 2003). Given its relatedness to economic evolutionary theory, one seedbed of path dependence research (e.g., Dosi, 1982; Witt, 1997), this certainly comes as no surprise. Nevertheless, the concept of path dependence has not yet been fully utilized in this stream of research either.
} 
time the cause of a future event, $\mathrm{C}$, etc., accumulating in a reaction chain: $\mathrm{A}>\mathrm{B}>\mathrm{C}>\mathrm{D}>$ $E>F$. Thus, initial event $A$ is expected to affect $B$, but it unintentionally triggers a multistage development. The final state or, better, an intermediate result can-very much like pursuing a lawsuit-be traced back to the releasing event. This intermediate state is also likely to shape future action; it is, however, not in any way locked in or inefficient.

In contrast to the path dependence model advanced above, the intermediate state of a sequence of causal reactions is not reached by increasingly reproducing a specific pattern, and there is no connecting logic that explains the succession of the singular sequences. Although the idea of reactive sequences doubtless provides insights into the evolvement of historical processes, it does not fit into a theory of path dependence. Without path drivers and the causal logic of a lock-in, a theory of organizational paths loses its very point.

Furthermore, the sequence argument raises some conceptual questions. First of all, sequences seem simply to occur. In contrast to processes explained by the regime of selfreinforcing mechanisms, the concept of causal reactive chains does not provide a logic that explains why the sequences take place in this way and not in another way. Why do reactive sequences accumulate? Superimposing, ex post, a trajectory on reactive sequences does not provide an explanation. Another problem is generalization. A theory of path dependence aims at explaining a particular class of processes (Pettigrew, Woodman, \& Cameron, 2001). Drawing on reactive sequences does not, however, transcend a singular case: singular reasons are supposed to explain singular events only.

\section{Institutionalizing}

Contextual shaping forces play a major role in neoinstitutional theory, and its concept of institutionalization also seems to come close to path dependence (e.g., Powell \& DiMaggio, 199l; Scott, 2001; Tolbert \& Zucker, 1996). Most important, this theory highlights the relevance of the symbolic-normative environment of organizations and how this influences the formal and informal structuring of organizations over time. Apart from the pace of the development (Lawrence et al., 2001), it addresses institutional in- ertia and stability by revealing how a specific organizational structure or form becomes sedimented and taken for granted over time, preferably across sets of organizations.

While neoinstitutional theory elucidates imprinting and stabilizing processes and, in particular, sensitizes us to the relevance of symbolicnormative contexts (e.g., Hargadon \& Douglas, 2001), in its present form it does not address the systemic logic of an escalating reinforcement of an action pattern or a path (see, however, Eden, 2004, and Holm, 1995). The theoretical focus, therefore, differs significantly and explains other constellations.

\section{AT THE HEART OF ORGANIZATIONAL PATH DEPENDENCE: SELF-REINFORCING MECHANISMS}

So far, we have conceptualized path-building processes as processes of a diminishing scope of action that unintentionally develop their own pull and are driven by positive feedback. It is a time-based theoretical concept differentiating between different states of flexibility/choice and stability/determinism, respectively. The dynomic eventually flips over into rigidity. At their heart, such processes can be explained by one or a combination of several self-reinforcing social mechanisms. In this section we elaborate on these mechanisms in an organizational context. $^{5}$

In the field of technology development and diffusion, different types of self-reinforcing dynamics have been identified (Arthur, 1994; Cowan, 1990; David, 1985; Katz \& Shapiro, 1985; North, 1990). Since they have been developed at the market level, these mechanisms cannot readily be transferred to organizational analysis. In our view four mechanisms in particular are likely to contribute to the development of organizational path dependence: coordination effects, complementarity effects, learning effects, and adaptive expectation effects. Below we aim to combine different streams of thought to build a framework of self-reinforcing dynamics at the level of single organizations and organizational subunits. We discuss these four

\footnotetext{
${ }^{5}$ For the more general debate on social mechanisms in organization theory, see, for instance, Pajunen (2008).
} 
mechanisms and show how they apply to organizational settings.

\section{Coordination Effects}

Initially put forward in institutional economics (North, 1990), these effects relate to the heart of organizational functioning. They build on the benefits of rule-guided behavior: the more actors adopt and apply a specific institution (i.e., an organizational rule or routine), the more efficient the interaction among these actors is, since the behavior of the actors is rule guided and can therefore be anticipated and reactions can be considered in advance. Coordination costs can be significantly reduced. In consequence, it becomes more attractive to adopt these rules the more other individuals also follow them.

The best-known illustrative example of this effect at the institutional level is the decision regarding right-hand traffic versus left-hand traffic; the institution became fixed early on because of the obvious benefits of following ituncertainties involved in human interaction could successfully be reduced (North, 1990: 23). Another well-known example that applies directly to the level of single organizations is working-time regimes, which guarantee efficient cooperation. There is a striking similarity to the economies of scale effect (North, 1990): increasing the number of participants results in decreasing (coordination) cost per unit.

Miller and Friesen (1984) developed the concept of internal consistency, which comes very close to that of coordination effects. This proposition stresses the advantages of an internal fit among the various elements of an organization (see also Miller, 1992). Coordination effects thus result from the benefits of following the same single rule or set of related rules to which others are willing to conform. As a result, through the advantages of continued replication, a specific pattern of practices is likely to become fixed. The fixing power of such arrangements has been proved in cases where organizational members have recognized new challenges and set out to change their practices but failed to do so because they could not get rid of their wellattuned activity sets and routines.

A striking example of such path dependence was provided by Tripsas and Gavetti (2000), who portrayed the difficulties Polaroid experienced in changing their $R \& D$ priorities into a new product development competence. Similarly, Gilbert (2005) described newspaper companies who stuck to self-reinforcing rules for producing a newspaper and thereby became unable to exploit new online opportunities. More recently, Koch (2008) provided evidence of similar patterns in German quality newspapers. Adopting joint rules of quality journalism brought about significant coordination advantages and the lasting constitution of a once successful business model. Nowadays, the flip side of this path is broadly discussed.

\section{Complementary Effects}

A well-known explanation for complementarities are economies of scope, which exist when the cost of producing and selling two or more goods or services together is lower than the cost of producing and selling them separately (Panzar \& Willig, 1981). On a more general level, complementarities mean synergy resulting from the interaction of two or more separate but interrelated resources, rules, or practices (Pierson, 2000; Stieglitz \& Heine, 2007). In the case of complementarities, the advantages of repeatedly combining interrelated activities do not simply add up; they produce an additional surplus: $K_{(x+y)}>K_{(x)}+K_{(y)}$. Take, for instance, marketing skills and R\&D capabilities, which may add up to a "core competence" (Prahalad \& Hamel, 1990) of a company or a division. David (1994: 214) calls such combinations "institutional clusters." In complementary settings selfreinforcing processes occur when routines and/or practices are interconnected in such a way that it becomes ever more attractive to exploit the synergies or-when referring to the reverse side-to save misfit costs caused by solutions deviating from the established cluster/ organizational capability. As a result, distinct sets of activity patterns become progressively dominant (Leonard-Barton, 1995) and, additionally, deeply embedded in an organization ("deep structure")-that is, they become organizationally path dependent.

There are many other examples that can further illustrate this effect. Take, for instance, "Fordism," which is characterized by complementary management systems in human resources (hiring and firing of low skilled labor), operations (mass production), and organization 
(hierarchy of control), and which for quite some time constituted, through repeated practicing, a specific capability amounting to a competitive organizational advantage. Ultimately, the institutional cluster became path dependent (Piore \& Sabel, 1984).

\section{Learning Effects}

The learning effect theory holds that the more often an operation is performed, the more efficiency will be gained with subsequent iterations. The operation becomes more skillfully performed (faster, more reliable, and with less errors), which, in turn, means decreasing average costs per unit of output (Argote, 1999). And the more attractive the chosen solution becomes because of accumulated skills and decreasing cost, the less attractive it is to switch to new learning sites (where the actors would have to start from scratch). Only sticking with the once chosen solution promises continued returnsalthough, as is well known, the resulting cost curve flattens after a while.

Self-reinforcing learning effects can be found at various organizational levels. A well-known example from organizational learning points to the fact that a focus on the advantages of exploitative learning may increasingly drive out explorative learning (March, 1991, 2006). For various reasons (e.g., the prevailing organizational culture and reward system) the motivation to improve everyday practices is likely to gain more acceptance or legitimacy (and, thus, more rewards) from the organization, whereas the motivation to look for fresh alternatives and to critically examine well-established organizational practices is likely to shrink progressively. This myopia or preference for repetitive exploitative learning builds on the self-reinforcing dynamics of learning effects, eventually ending up in on organizational path along the familiar practices.

A related effect has been highlighted by the "architecture of simplicity" (Miller, 1993), in which an organization develops a successful set of strengths and tends to focus all learning abilities on refining this success; it exploits these strengths through gaining learning effects while neglecting other opportunities. The exploitation is easier (more efficient) the simpler the institutional cluster; therefore, the selfreinforcing dynamics bring about unintended increasing simplicity. Ultimately, "it turns into a monolithic, narrowly focused version of its former self, converting a formula for success into a path toward failure" (Miller, 1993: 116). Learning effects are often reinforced and extended by earnings from coordination costs and complementarities.

\section{Adaptive Expectation Effects}

These self-reinforcing effects relate to the interactive building of preferences. With this concept, as opposed to neoclassical economics, individual preferences are not considered to be fixed; instead, they are assumed to vary in response to the expectations of others. Often quoted examples highlight the need for social belonging and the desire to end up on the winning side. The more people are expected to prefer a particular product or service (and not another), the more attractive that product or service becomes (Leibenstein, 1950). Since users are often uncertain about the right choice, they feel rewarded by the fact that others are likely to prefer the same. Because of this self-reinforcing dynamic, a dominant solution is likely to emerge, more often than not by way of a selffulfilling prophecy (in most cases on the basis of more or less random first choices and from hearsay).

In the context of organizations, the informal diffusion of best practices often follows this logic (Szulanski, 1996). Organizational members are willing to adopt these practices because they expect others to do the same and wish to end up on the side of the winners. This tendency is reinforced by other drivers, such as legitimacy seeking or signaling; individuals or subsystems not subscribing to the mainstream practices are afraid of losing legitimacy and-if associated with failure- of becoming stigmatized as "outsiders" (Kulik, Bainbridge, \& Cregan, 2008).

Early on, McGregor's (1960) Theory X nicely illustrated the dynamics of such self-reinforcing adaptive expectations and subsequent selffulfilling prophecies in organizations. The starting point of his Theory $\mathrm{X}$ spiral is managers' implicit assumptions about the nature of their employees-as being interested only in monetary rewards, hating to take on responsibility, and shirking wherever they can. This implicit theory of human behavior not only defines the set of expected managerial behaviors but also 
essentially frames management's decisions on reward systems and organizational design (in particular, a strong emphasis on control and authority), which, in turn, evoke corresponding reaction patterns (especially passivity, indolence, and apathy). Observing those reactions is likely to confirm and reconfirm exactly those assumptions about behavior managers have made, based on their implicit Theory X. These confirmed expectations then reinforce the emphasis on restrictive organizational structures and controls, thereby unconsciously advancing a vicious circle (see also Leonard-Barton, 1995; Masuch, 1985; Repenning \& Sterman, 2002). In this case a dominant organizational design emerges because of $\alpha$ self-reinforcing spiral that is based on "expectations of expectations" (Luhmann, 1995).

\section{Adding an Enhancing Context?}

Some authors add contextual conditions as a further reinforcing effect of and in institutions. Pierson (2000), for instance, highlights institutional density as a salient determinant likely to converge into self-reinforcing effects in organizations. In his view organizations (in particular, formal political institutions) are more prone to bring about path-building forces than markets, because they act in "a far, far murkier environment" (Pierson, 2000: 260) with weaker forces to correct inefficient courses of action over time. The complexity of organizational goals and the uncertainty of the causal links between actions and outcomes render the organizational field inherently ambiguous, and organic corrections of inefficient action are less likely to occur here than in markets. Therefore, practices, once established, gain momentum more easily and create a fertile ground for developing increasing returns or other types of positive self-reinforcing feedback. More generally, Pierson considers ambiguity and complexity important conditions, which amount to self-reinforcing effects and subsequent path dependence.

Although addressing doubtless significant contextual conditions for path development, the conditions of ambiguity and complexity should not be misconceived as self-reinforcing mechanisms in their own right. This also holds true for other factors addressed in the literature as selfreinforcing dynamics, such as "uncertain expectations" or "power structure" (Beyer, 2005). These are relevant contextual factors, but they should not be equated with self-reinforcing mechanisms. Enhancing contexts-however important they may be-neither lead directly to path dependence nor represent a necessary or even sufficient condition for the occurrence of path dependence (see also Arthur, 1989). A theory of organizational path dependence has to differentiate properly between self-reinforcing mechanisms on the one hand and enabling institutional contexts on the other. In consequence, Pierson's insights should encourage further research to explore the contextual conditions enhancing (or hindering) the unfolding of selfreinforcing mechanisms and subsequent constitution of organizational paths.

\section{IMPLICATIONS FOR MANAGEMENT AND RESEARCH}

Path dependence and its far-reaching consequences doubtlessly constitute an issue of high relevance in strategic management and organizational decision making. From a managerial point of view, the fatal consequences of being locked in raise the pressing question of whether organizational paths can be dissolved or in any way escaped. It is true that no path is forever, but this is no relief from the perspective of $a$ particular organization, since path dependence may exist for quite some time.

Path dissolution may occur through unforeseen exogenous forces, such as shocks, catastrophes, or crises; these are likely to shake the system, thereby causing the organization to break away from the path (Arthur, 1994: 118). However, path dissolution may also occur because of an insidious change in organizational demography or the "incomplete" socialization of new organizational members (Tolbert, 1988). In this vein, Castaldi and Dosi (2006) refer to the possibility of coincidental delocking in terms of a by-product of other organizational decisions. A nice illustration of such coincidental path dissolution at an organizational level is provided by the Intel case and its moves in the memory business (Burgelman, 1994, 2002; Burgelman \& Grove, 1996). With this perspective, however, path dissolution amounts to an accidental process, be it revolutionary or evolutionary, which-nobody knows-may or may not occur. Adopting this view clearly has a fatalistic or at least a passive flavor to it. We are condemned to 
wait, probably for a long time since we know such events are rare. The firm may go bankrupt long before a disrupting event occurs. An active and alert attitude thus seems imperative.

Facing strategic rigidity or even a threat to the organization's survival, decision makers would certainly be eager to learn more about possible interventions designed to escape or unlock organizational paths. But can organizations actually break path dependence? This is an intricate endeavor, since the idea of deliberately breaking a path is self-contradicting in a way. If we define path dependence as a situation in which individual actors or organizations have lost their power to choose among alternatives, then the assumption that the same actors can unlock the path is obviously inconsistent. Pathdependent behavior, strictly speaking, excludes path-breaking behavior. The idea of unlocking organizational paths, therefore, can only work if we put the mechanisms of deterministic pattern reproduction into perspective. In other words, it is necessary to construe and integrate an exogenous perspective-that is, an activity that is not under the regime of path dependence. Such integration of an external lens or-if you like- $a$ "second-order observation" (von Foerster, 1991) enables knowledgeable agents to reflect practices in terms of path dependence and potentially opens a window for path-breaking activities.

\section{Deliberately Breaking Organizational Paths}

When discussing the actual possibilities of dissolving organizational paths, we need to clarify what path breaking in an organizational context means precisely. Is it the destruction of $\alpha$ rigidified action pattern? Does it mean restoring the situation as depicted in Phase I? Is it the broadening of the "corridor" in Phase III? Is it the realized switch to a superior alternative? From our point of view, each of these alternatives is not exclusive. Rather, path breaking can vary in intensity and complexity. Without excluding more complex cases, we therefore suggest defining a minimum condition for a situation to be categorized as path breaking. Since the process of becoming path dependent has been framed as progressively eliminating the scope of decision making, this minimum condition is the effective restoration of a choice situation-the insertion of at least one alternative course of action. However, opening the window for an alternative is necessary but not sufficient. The new alternative has to be a superior one (Arthur, 1994), because implanting an inferior one would not constitute a real choice.

The suggested theory of path dependence can inform the endeavor to intentionally unlock organizational paths. As already pointed out, the major drivers rendering a process path dependent are self-reinforcing dynamics. By implication, the possibility of escaping from or breaking a path depends very much on interrupting the logic and the specific energy of the selfreinforcing patterns of the process in question. The first step in any path-breaking intervention, thus, requires understanding and reflecting on not only the fact of being path dependent but also the drivers that made this happen. At the same time, this step brings the necessary distancing from the replicating dynamics. Reflecting on the practice that is usually taken for granted indicates taking a critical stance (Moon, 1999; Schön, 1983) by changing the mode of activity: from doing (operational mode) to observing and reflecting (observational mode), thereby gaining access to the closed dynamics.

Understanding self-reinforcing dynamics requires theoretical knowledge as well as practical skills and abilities. This is all the more true since the organizational dynamics of path formation are more often than not hidden dynamics. Subconscious blinders, perceptual defense, and blind spots tend to inhibit reflection processes (Saffold, 1988; Sørensen, 2002). As a consequence, in many cases a special effort is needed to get in touch with the hidden agenda. Tools have been developed to facilitate such processes. Assumption surfacing, for instance, is a well-known technique designed to make hidden patterns in organizational settings accessible, to open them up for critical reflection, and to put them on the organizational discourse agenda (Kettinger, Teng, \& Guha, 1997; Mason \& Mitroff, 1981).

Beyond discourse, however, reflecting pathbounded practices often requires addressing the emotional side of inertial organizational patterns as well. Organizations frequently resist reflecting on hidden features. For instance, in their analysis of the Intel case, Burgelman and Grove (1996: 15) found that "emotional attachment on the part of the top management to the business" was intertwined with inertial self- 
perceptions. Dissolving and/or altering such emotional barriers often requires special approaches-in particular, clinical approaches, such as "reframing" (Bandler \& Grinder, 1982), or even psychoanalytical techniques (Kets de Vries, 2006). Such interventions may help to unlock emotional blinders and to reflect the dominant framing manifested in replicative practices.

As is well-known, such individual-centered approaches are limited. In some cases the whole system is controlled by a regime of unwritten rules that suggest refraining from self-reflection (Scott-Morgan, 1994). Communication research has revealed that such closing behavior is often caused by paradoxical interactions, such as a double bind (Hennestad, 1990; Watzlawick, 1963), basically maintained and fixed by self-reinforcing behavioral patterns. So-called systemic approaches (Campbell, Coldicott, \& Kinsella, 1994; Selvini-Palazzoli, 1986) react to exactly this wellknown denial. In these approaches a totally new type of intervention has been developed-the paradoxical intervention. This is a disguised intervention designed to irritate the closed selfreinforcing system from outside. The change agent no longer tries to persuade the system to reflect and modify its hidden rules; rather, he or she "asks" the system to produce more of the behavior that is suggested should be changed. The underlying idea is that a prescribed resistance shifts the logic; it ceases to be resistance and becomes compliance (Watzlawick, Weakland, \& Fisch, 1974). On the other hand, resisting this prescription means changing. In selfreinforcing systems these paradoxical interventions bring about a kind of pattern implosion, likely to shake the system of long-standing "defensive routines" (Argyris, 1990) into a new configuration and to open the window of opportunity for path-breaking changes. A paradoxical intervention comes as a surprise to the system; it attempts to stop the self-reinforcing dynamics by advancing an implosion of the routinized rigidity.

Such interrupting approaches potentially reopen the scope of action. Opening the scope, however, does not automatically imply unlocking a path. Whether or not an existing organizational path can actually be broken in the sense defined above basically depends on the reversibility of the process. The path-breaking endeavor cannot ignore the history that brought about path dependence. The chance of actually restoring choice depends on the character of the self-reinforcing dynamics and the possibility of creating a new advantageous situation. Major features here are resource commitment, reversibility, and transferability of experience (Arthur, 1994; Ghemawhat, 1991; Gilbert, 2005; Karim \& Mitchell, 2000). In cases where learning effects are the major drivers of path dependence, the reversibility is at least questionable. Learning effects are acquired in a specific field of practice and cannot easily be transferred to a new context (of a new alternative). Setting up a new course of action takes quite some time to match the learning effects of the existing course (even when it has been proved inferior). In those cases creating an effective alternative for the restoration of choice requires an extra effort-a (possibly costly) subsidy to help the new alternative catch up with the existing one (Arthur, 1994).

The situation is different for other selfreinforcing mechanisms-for instance, for coordination effects. The logic of this driver very much depends on the willingness to conform to rules. What is required here, therefore, is the willingness to switch to a new regime of rules mandated by a change agent or a project group. As Arthur (1994) points out, this is more likely to happen the higher the certainty that the others also prefer the new alternative regime of rules. In cases where this certainty is missing (or rule takers are at least uncertain about the action preferences of others), the situation is difficult to change, because actors wait for more certainty. In all of these cases, additional initiatives are required to reduce uncertainty about others' action.

One may argue that unlocking or breaking on organizational path should be easier than escaping a technological or market lock-in. Organizations by their very nature are characterized by a central authority and hierarchical control, which allows (top) management to create viable organizational alternatives in terms of incentive systems, formal rules, or planning procedures. Organizations rely on command and control, even most new organizational forms. Nevertheless, because of informal processes, the lack of transparency, and unintended consequences of actions in organizations, it is unrealistic to assume that the development of an organization is completely under management's control. The tendency toward diminishing control, actual 
control loss, and the illusion of control have been long-standing issues in organizational research (see, for instance, Downs, 1967, and Streatfield, 2001). In consequence, the scope for an organization to unlock path dependence simply by order is clearly limited. More often than not, such merely formal approaches will fail because-as depicted above-it is so difficult to stop self-reinforcing processes in organizations. Special techniques are required.

\section{Researching Organizational Paths}

The suggested three-stage model of organizational path dependence and its focus on selfreinforcing mechanisms not only provide $a$ platform for considering path-breaking interventions but also suggest guidelines for further research on organizational paths. According to this framework, any attempt to prove the claim of path dependence needs to cover the following three features, in a way reversing the process depicted in Figure 1.

The first step of a thorough path analysis is the identification of strategic persistence or operational rigidity of or within a particular organization. Discovering such structural or institutional inertia allows the researcher to assert path dependence. Because the logic of hyperstability is often hidden, inert practices are easier to uncover or make visible in situations of radical change (e.g., Tushman, Newman, \& Romanelli, 1986). However, organizational paths can also surface in incremental or even creeping change processes. In any case, the contrafactual maintenance of a specific pattern is an indicator of a path-induced, potentially inefficient organizational lock-in. With regard to the efficiency aspect, at the very least, the existence of a superior alternative that the organization is unable to pursue has to be demonstrated. A major challenge is presented by the case of potential or strategic inefficiency-that is, proving that the replicate behavioral pattern is likely to damage the organization in the future. In these cases, where no empirical proofs can be provided, it becomes a matter of good reasoning to build a convincing case.

The second major element of an advanced path analysis is the identification, exploration, and reconstruction of the self-reinforcing feedback mechanisms possibly underlying the organizational rigidity in question. The identification or detection of one or more such mechanisms at work is a complex task that requires recognizing patterns in the broad flow of everyday practices. If there are no self-reinforcing mechanisms "at work," the presumption of an existing organizational path cannot be substantiated and has to be rejected.

The third essential part of a systematic path analysis is the search for a triggering event that was likely to have set the path-building process in motion. Tracer studies (e.g. Lee, 1999) may help to identify these initial events mostly unknown to the actors. Also, special attention has to be devoted to identifying the critical juncture at which a self-reinforcing process leading to organizational path dependence was activated. It is here where the first working of one or more self-reinforcing mechanisms can be uncovered.

These three elements offer a rough guideline for both explanatory and exploratory research on organizational path dependence. Because of the process character of the framework, a longitudinal research design is required, which traces sequences of events and actions in organizations (e.g., time chronologies, simple and complex time series). Only the examination of these detailed processes in time (and space) will allow us to identify and explicate the working of the fundamental social mechanism(s) underlying the constitution of organizational path dependence "from micro behaviors to system dynamics, and back" (Castaldi \& Dosi, 2006: 108).

\section{CONCLUSIONS}

A detailed conception of organizational path dependence has much to offer when we are aiming to solve the puzzle of how organizations become locked in and adhere contraintuitively to historical solutions. To this end, we have defined organizational path dependence as a process that (1) is triggered by a critical event leading to a critical juncture; (2) is governed by a regime of positive, self-reinforcing feedback constituting a specific pattern of social practices, which gains more and more predominance against alternatives; and (3) leads, at least potentially, into an organizational lock-in, understood as a corridor of limited scope of action that is strategically inefficient. The proposed framework not only provides a deeper understanding of the historicity of inertial phenomena beyond the general principle that "history matters" but 
also pushes the explanation beyond such wellknown concepts as organizational imprinting, institutional legacy, and structural inertia.

This framework of path dependence also offers insights into the possibilities and limitations of breaking out of organizational path dependence. In particular, path breaking requires a thorough understanding of the social mechanisms driving the path process. Understanding these mechanisms, in turn, provides a platform for developing path-breaking interventions.

Organization research focusing on path dependencies and path breaking would nicely supplement not only the present trend toward process studies, with their inevitable historical component (e.g., Pettigrew et al., 2001; Van de Ven \& Poole, 2005), but also studies of organizational practices and their replicate dynamics (e.g., Feldman \& Pentland, 2003; Jarzabkowski, 2008; Lawrence et al., 2001). In both cases the theory of organizational path dependence would help to focus on particular types of dynamics and, thus, would complement rather than substitute for other process theories of organizations. However, the conditions that are conducive to path dependence and possible ways of unlocking paths await further exploration.

A further challenging theoretical question is whether the emergence of paths does not simply occur but can also be deliberately brought about. The idea of (intentional) path creation was introduced by Garud and Karnøe (2001), who referred to Schumpeter (1942) and his conception of a "destroying" entrepreneurship. Creative agency and the power of generating momentum are seen as basic ingredients for path creation, although entrepreneurship, as influenced by its own history and important institutions, may well also be a source of path dependence (Staber, 2005).

Another important issue addresses the level of analysis. Our three-stage model aims at explaining path-building processes of and in organizations. However, other levels of analysis are also of great relevance-particularly the individual level, the network level, and the field level. Organizational members, with their cognitive schemata, learning habits, response patterns, and so forth, do play a role in path-building processes in organizations. Although a vast body of research on individual rigidities is available (see Huff \& Huff, 2000: 46-59, for a review), individual path research stills awaits elaboration.
The same is true of interorganizational relations. Nowadays, many organizations are embedded in more or less complex networks of relationships. Collaborative relationships are likely to become path dependent too, thereby affecting the development of an organization (and vice versa). Some network-related studies of path dependence are already available, highlighting, for instance, lock-ins and lock-outs in the course of the development of a network (Gulati, Nohria, \& Zaheer, 2000) or the possibility of arising network inertia (Kim, Oh, \& Swaminathan, 2006). Others shed light on the impact of network embeddedness on organizational path dependence (e.g., Walker, Kogut, \& Shan, 1997). But, as in the case of most studies at the organizational level of analysis, these tend to consider path dependence in the sense of history matters only, and not in the specified way suggested by the explanatory concept advanced here.

The third level important for organizational path analysis is the field or industry, which has been addressed by the majority of path dependence research so for (starting with David, 1985). Research already evidences the significance of the field for explaining organizational inertia, beyond the influence of technological path dependencies. The well-known study of the Scottish knitwear industry (Porac, Thomas, Wilson, Paton, \& Kaufer, 1995), for example, convincingly demonstrates that it was primarily the value system of the industry and not the individual organization that brought about inertia. Another example is Hollingsworth's (2006) study of leading research organizations that were involved in major scientific discoveries. This study not only points to the path-dependent development of the organizations (and even of single laboratories) investigated but also to that of the institutional fields in which they were embedded.

Future research should account more explicitly for these different levels and their interplay, which may well amount to "cross-catalytic feedback" (Paul David, personal communication) between not only these levels but also organizational and technological path processes. Beyond this, we are convinced that more rigorous research on organizational paths can enrich organization science significantly, as well as our understanding of puzzling rigidities in organizational life. 


\section{REFERENCES}

Antonelli, C. 1999. The economics of path-dependence in industrial organization. International Journal of Industrial Organization, 15: 643-675.

Argote, L. 1999. Organizational learning: Creating, retaining and transferring knowledge. Boston: Kluwer Academic.

Argyris, C. 1990. Overcoming organizational defenses. Boston: Prentice-Hall.

Arrow, K. J. 2004. Path dependence and competitive equilibrium. In T. W. Guinnane, W. A. Sundstrom, \& W. C. Whatley (Eds.), History matters: Essays on economic growth, technology, and demographic change: 23-35. Stanford, CA: Stanford University Press.

Arthur, W. B. 1989. Competing technologies, increasing returns, and lock-in by historical events. Economic Journal, 99: 116-131.

Arthur, W. B. 1994. Increasing returns and path dependency in the economy. Ann Arbor: University of Michigan Press.

Bandler, R. J., \& Grinder, J. 1982. Reframing: Neurolinguistic programming and the transformation of meaning. Moab, UT: Real People Press.

Bassanini, A. P., \& Dosi, G. 2001. When and how chance and human will can twist the arms of Clio: An essay on path dependence in a world of irreversibilities. In R. Garud \& P. Karnøe (Eds.), Path dependence and creation: 4l-68. Mahwah, NJ, \& London: Lawrence Erlbaum Associates.

Beckman, C. M., \& Burton, M. D. 2008. Founding the future: Path dependence in the evolution of top management teams from founding to IPO. Organization Science, 19: 3-24.

Beer, M., \& Nohria, N. (Eds.). 2000. Breaking the code of change. Boston: Harvard Business School Press.

Beyer, J. 2005. Pfadabhängigkeit ist nicht gleich Pfadabhöngigkeit! Wider den impliziten Konservatismus eines göngigen Konzepts [Path dependence does not equal path dependence! Against the conservatism implicit in this concept]. Zeitschrift für Soziologie, 34(1): 5-21.

Boeker, W. 1989. The development and institutionalization of subunit power in organizations. Administrative Science Quarterly, 34: 388-410.

Bruggeman, D. 2002. NASA: A path dependent organization. Technology in Society, 24: 415-431.

Burgelman, R. A. 1994. Fading memories: A process theory of strategic business exit in dynamic environments. Administrative Science Quarterly, 39: 24-56.

Burgelman, R. A. 2002. Strategy as vector and the inertia of coevolutionary lock-in. Administrative Science Quarterly, 47: 325-357.

Burgelman, R. A. In press. Strategic consequences of coevolutionary lock-in: Insights from a longitudinal process study. In G. Schreyögg \& J. Sydow (Eds.), The hidden dynamics of path dependence. London: PalgraveMacmillan.

Burgelman, R. A., \& Grove, A. S. 1996. Strategic dissonance. California Management Review, 38(2): 8-25.
Callon, M. 1992. The dynamics of techno-economic networks. In R. Coombs, P. Saviotti, \& V. Walsh (Eds.), Technological change and company strategies: 72-102. London: Academic Press.

Campbell, D., Coldicott, T., \& Kinsella, K. 1994. Systemic work with organisations. London: Karnac Books.

Carroll, G. R., \& Harrison, J. R. 1994. On the historical efficiency of competition between organizational populations. American Journal of Sociology, 100: 720-749.

Castaldi, C., \& Dosi, G. 2006. The grip of history and the scope of novelty: Some results and open questions of path dependence in economic processes. In A. Wimmer \& R. Kössler (Eds.), Understanding change: Models, methodologies, and metaphors: 99-128. Basingstoke, UK: Palgrave Macmillan.

Child, J. 1997. Strategic choice in the analysis of action, structure, organizations and environment: Retrospect and prospect. Organization Studies, 18: 43-76.

Collier, R. B., \& Collier, D. 1991. Shaping the political arena: Critical junctures, the labor movement, and regime $d y$ namics in Latin America. Princeton, NJ: Princeton University Press.

Collinson, S., \& Wilson, D. C. 2006. Inertia in Japanese organizations: Knowledge management routines and failure to innovate. Organization Studies, 27: 1359-1387.

Cowan, R. 1990. Nuclear power reactors: A study in technological lock-in. Economic Journal, 106: 541-567.

Crouch, C., \& Farrell, H. 2004. Breaking the path of institutional development? Alternatives to the new determinism. Rationality and Society, 16: 5-43.

Cusumano, M. A., Mylonadis, Y., \& Rosenbloom, R. S. 1992. Strategic maneuvering and mass-market dynamics: The triumph of VHS over Beta. Business History Review, 66: 51-94.

David, P. A. 1985. Clio and the economics of QWERTY. American Economic Review, 75: 332-337.

David, P. A. 1986. Understanding the economics of QWERTY: The necessity of history. In W. N. Parker (Ed.), Economic history and the modern economist: 30-49. Oxford: Blackwell.

David, P. A. 1994. Why are institutions the "carriers of history"? Path dependence and the evolution of conventions, organizations and institutions. Structural Change and Economic Dynamics, 5: 205-220.

Dosi, G. 1982. Technological paradigms and technological trajectories: A suggested interpretation of the determinants and directions of technical change. Research Policy, 11: 147-162.

Dosi, G. 1997. Opportunities, incentives and the collective patterns of technological change. Economic Journal, 107: $1530-1547$.

Downs, A. 1967. Inside bureaucracy. Boston: Little, Brown.

Eden, L. 2004. Whole world on fire: Organizations, knowledge, and nuclear weapons devastation. Ithaca, NY: Cornell University Press.

Feldman, M. S., \& Pentland, B. 2003. Reconceptualizing or- 
ganizational routines as a source of flexibility and change. Administrative Science Quarterly, 48: 94-118.

Garud, R., \& Karnøe, P. 2001. Path creation as a process of mindful deviation. In R. Garud \& P. Karnøe (Eds.), Path dependence and creation: 1-38. Mahwah, NJ, \& London: Lawrence Erlbaum Associates.

Ghemawat, P. 1991. Flexibility and commitment: The dynamics of strategy. New York: Free Press.

Giddens, A. 1984. The constitution of society: Outline of the theory of structuration. Cambridge: Polity Press.

Gilbert, C. G. 2005. Unbundling the structure of inertia: Resource versus routine rigidity. Academy of Management Journal, 48: 741-763.

Gresov, C., Haveman, H. A., \& Olivia, T. A. 1993. Organizational design, inertia and the dynamics of competitive response. Organization Science, 4: 181-208.

Gulati, R., Nohria, N., \& Zaheer, A. 2000. Strategic networks. Strategic Management Journal, 21: 203-215.

Guler, I. 2007. Throwing good money after bad? Political and institutional influences on sequential decision making in the venture capital industry. Administrative Science Quarterly, 52: 248-285.

Hannan, M. T., \& Freeman, J. 1984. Structural inertia and organizational change. American Sociological Review, 49: 149-164.

Hannan, M. T., Plos, L., \& Carroll, G. R. 2004. The evolution of inertia. Industrial and Corporate Change, 13: 213-242.

Hargadon, A. B., \& Douglas, Y. 2001. When innovations meet institutions: Edison and the design of the electric light. Administrative Science Quarterly, 46: 476-501.

Helfat, C. E. 1994. Evolutionary trajectories in petroleum firm R\&D. Management Science, 40: 1720-1747.

Hennestad, B. W. 1990. The symbolic impact of double bind leadership: Double bind and the dynamics of organizational culture. Journal of Management Studies, 27: 265280.

Hilborn, R. C. 2004. A simple model for stochastic coherence and stochastic resonance. American Journal of Physics, 72: 528-533.

Hollingsworth, R. 2006. A path-dependent perspective on institutional and organization factors shaping major scientific discoveries. In J. Hage \& M. Meeus (Eds.) Innovation, science, and institutional change: 432-442. New York: Oxford University Press.

Holm, P. 1995. The dynamics of institutionalization: Transformation processes in Norwegian fisheries. Administrative Science Quarterly, 40: 398-422.

Huff, A. S., \& Huff, J. O. 2000. When firms change direction. Oxford: Oxford University Press.

Hughes, T. P. 1987. The evolution of large technological systems. In W. E. Bijker, T. P. Hughes, \& T. J. Pinch (Eds.), The social construction of technological systems: 51-82. Cambridge, MA: MIT Press.

Jarzabkowski, P. 2008. Shaping strategy as a structuration process. Academy of Management Journal, 51: 621-650.

Johnson, V. 2007. What is organizational imprinting? Cul- tural entrepreneurship in the founding of the Paris Opera. American Journal of Sociology, 113: 97-127.

Karim, S., \& Mitchell, W. 2000. Path-dependent and pathbreaking change: Reconfiguring business resources following acquistions in the U.S. medical sector, 1978-1995. Strategic Management Journal, 21: 1061-1081.

Katz, M. L., \& Shapiro, C. 1985. Network externalities, competition, and compatibility. American Economic Review, 75: $424-440$.

Kauffman, S. A. 1993. Origins of order: Self-organization and selection in evolution. Oxford: Oxford University Press.

Kaufman, H. 1995. The limits of organizational change. Edison, NJ: Transaction Books.

Kets de Vries, M. 2006. The leader on the couch: A clinical approach to changing people and organizations. West Sussex, UK: Wiley.

Kettinger, W. J., Teng, J. T. C., \& Guha, S. 1997. Business process change: A study of methodologies, techniques, and tools. MIS Quarterly, 21: 51-80.

Kim, T.-Y., Oh, H., \& Swaminathan, A. 2006. Framing interorganizational network change: A network inertia perspective. Academy of Management Review, 31: 704-720.

Koch, J. 2008. Strategic paths and media management: A path dependency analysis of the German newspaper branch of high quality journalism. Schmalenbach Business Review, 60: 51-74.

Kulik, C. T., Bainbridge, H. T. J., \& Cregan, C. 2008. Known by the company we keep: Stigma-by-association effects in the workplace. Academy of Management Review, 33: $216-230$.

Lawrence, T. B., Winn, M. I., \& Jennings, P. D. 2001. The temporal dynamics of institutionalization. Academy of Management Review, 26: 624-644.

Lee, T. W. 1999. Using qualitative methods in organizational research. Thousand Oaks, CA: Sage.

Leibenstein, H. 1950. Bandwagon, snob, and Veblen effects in the theory of consumers' demand. Quarterly Journal of Economics, 64: 183-207.

Leonard-Barton, D. 1995. Wellsprings of knowledge. Boston: Harvard Business School Press.

Luhmann, N. 1995. Social systems. Stanford, CA: Stanford University Press.

Mahoney, J. 2000. Path dependence in historical sociology. Theory and Society, 29: 507-548.

March, J. G. 1991. Exploration and exploitation in organizational learning. Organization Science, 2: 71-87.

March, J. G. 1994. A primer on decision making. New York: Free Press.

March, J. G. 2006. Rationality, foolishness, and adaptive intelligence. Strategic Management Journal, 27: 201-214.

Mason, R. O., \& Mitroff, I. I. 1981. Challenging strategic planning assumptions: Theory, cases and techniques. New York: Wiley.

Masuch, M. 1985. Vicious circles in organizations. Administrative Science Quarterly, 29: 14-33. 
McGregor, D. 1960. The human side of enterprise. New York: McGraw-Hill.

Merton, R. K. 1936. The unanticipated consequences of purposive social action. American Sociological Review, 1: 894-904.

Miller, D. 1992. Environmental fit versus internal fit. Organization Science, 3: 159-178.

Miller, D. 1993. The architecture of simplicity. Academy of Management Review, 18: 116-138.

Miller, D., \& Friesen, P. 1984. Organization: A quantum view. Englewood Cliffs, NJ: Prentice-Hall.

Moon, J. 1999. Reflection in learning \& professional development. London: Kogan Page.

Nelson, R. R., \& Winter, S. G. 1982. An evolutionary theory of economic change. Cambridge, MA: Harvard University Press.

Nooteboom, B. 1997. Path dependence of knowledge: Implications for the theory of the firm. In L. Magnusson \& J. Ottosson (Eds.) Evolutionary economics and path dependence: 57-78. Cheltenham, UK: Edward Elgar.

North, D. C. 1990. Institutions, institutional change and economic performance. Cambridge: Cambridge University Press.

Ortmann, G. 1995. Formen der Produktion: Organisation and Rekursivität [Forms of production: Organization and recursiveness]. Opladen: Westdeutscher Verlag.

Pajunen, K. 2008. The nature of organization mechanisms. Organization Studies, 29: 1449-1468.

Panzar, J. C., \& Willig, R. D. 1981. Economies of scope. American Economic Review, 71: 268-272.

Pettigrew, A. M., Woodman, R. W., \& Cameron, K. S. 2001. Studying organizational change and development: Challenges for future research. Academy of Management Journal, 44: 697-713.

Pierson, P. 2000. Increasing returns, path dependence, and the study of politics. American Political Science Review, 94: 251-267.

Pierson, P. 2004. Politics in time. Princeton, NJ: Princeton University Press.

Pindyck, R. S., \& Rubinfeld, D. L. 2005. Microeconomics (6th ed.). Upper Saddle River, NJ: Prentice-Hall.

Piore, M. J., \& Sabel, C. F. 1984. Second industrial divide: Possibilities for prosperity. New York: Basic Books.

Porac, J. F., Thomas, H., Wilson, F., Paton, D., \& Kaufer, A. 1995. Rivalry and the industry model of Scottish knitwear manufacturers. Journal of Management Studies, 26: $397-416$.

Powell, W. W., \& DiMaggio, P. (Eds.). 1991. The new institutionalism in organization analysis. Chicago: University of Chicago Press.

Prahalad, C. K., \& Hamel, G. 1990. The core competence of the corporation. Harvard Business Review, 68(3): 79-91.

Repenning, N. P., \& Sterman, J. D. 2002. Capability traps and self-confirming attribution errors in the dynamics of pro- cess improvement. Administrative Science Quarterly, 47: 265-295.

Ross, J., \& Staw, B. M. 1993. Organizational escalation and exit: Lessons from the Shorehand nuclear power plant. Academy of Management Journal, 36: 701-732.

Ruef, M. 1997. Assessing organization fitness on a dynamic landscape: An empirical test of the relative inertia thesis. Strategic Management Journal, 18: 837-853.

Saffold, G. S. 1988. Culture traits, strength, and organizational performance: Moving beyond "strong" culture. Academy of Management Review, 13: 546-558.

Schön, D. A. 1983. The reflective practitioner. New York: Basic Books.

Schreyögg, G., \& Kliesch-Eberl, M. 2007. How dynamic can capabilities be? Strategic Management Journal, 28: 913933.

Schumpeter, J. A. 1942. Capitalism, socialism and democracy. New York: Harper \& Row.

Scott, R. 2001. Organizations and institutions (2nd ed.). Thousand Oaks, CA: Sage.

Scott-Morgan, P. 1994. The unwritten rules of the game: Master them, shatter them and break through the barriers to organizational change. New York: McGraw-Hill Professional.

Selvini-Palazzoli, M. 1986. The hidden games of organizations. New York: Random House.

Sewell, W. H., Jr. 1996. Three temporalities: Toward an eventful sociology. In T. J. McDonald (Ed.), The historic turn in the human sciences: 245-280. Ann Arbor: University of Michigan Press.

Sørensen, J. B. 2002. The strength of corporate culture and the reliability of firm performance. Administrative Science Quarterly, 47: 70-91.

Staber, U. 2005. Entrepreneurship as a source of path dependency. In G. Fuchs \& P. Shapira (Eds.), Rethinking regional innovation and change: Path dependency or regional breakthrough? 107-126. New York: Springer.

Staw, B. W. 1976. Knee deep in the big muddy: A study of escalating commitment to a chosen course of action. Organizational Behavior and Human Performance, 16: 27-44.

Stieglitz, N., \& Heine, K. 2007. Innovations and the role of complementarities in a strategic theory of the firm. Strategic Management Journal, 28: 1-15.

Stimpert, J. L., Wasserman, M. E., \& Jayaran, M. 1998. Strategic trajectories and patterns of innovation. In G. Hamel, C. K. Prahalad, H. Thomas, \& D. O'Neal (Eds.), Strategic flexibility: Managing in turbulent environments: $51-73$. New York: Wiley.

Stinchcombe, A. 1965. Social structures and organizations. In J. G. March (Ed.), Handbook of organizations: 142-193. Chicago: Rand McNally.

Streatfield, P. J. 2001. The paradox of control in organizations. New York: Routledge.

Szulanski, G. 1996. Exploring internal stickiness: Impediments to the transfer of best practices within the firm. Strategic Management Journal, 17(Winter Special Issue): 27-43. 
Teece, D. J., Pisano, G., \& Shuen, A. 1997. Dynamic capabilities and strategic management. Strategic Management Journal, 18: 509-533.

Thelen, K. 1999. Historical institutionalism and comparative politics. Annual Review of Political Science, 2: 369-404.

Tolbert, P. S. 1988. Institutional sources of organizational culture in major law firms. In L. G. Zucker (Ed.), Institutional patterns and organizations: 101-113. Cambridge, MA: Ballinger.

Tolbert, P. S., \& Zucker, L. 1996. The institutionalization of institutional theory. In S. R. Clegg, C. Hardy, \& C. E. North (Eds.), Handbook of organizational studies: 175190. London: Sage.

Tripsas, M., \& Gavetti, G. 2000. Capabilities, cognition and inertia: Evidence from digital imaging. Strategic Management Journal, 21: 1147-1161.

Tushman, M. L., Newman, W. H., \& Romanelli, E. 1986. Convergence and upheaval: Managing the unsteady pace of organizational evolution. California Management Review, 29(1): 29-44.
Van de Ven, A. H., \& Poole, M. S. 2005. Alternative approaches for studying organizational change. Organization Studies, 26: 1377-1404.

Volberda, H. W., \& Lewin, A. Y. 2003. Co-evolutionary dynamics within and between firms: From evolution to co-evolution. Journal of Management Studies, 40: 2111-2136.

von Foerster, H. 1991. Through the eyes of the other. In F. Steier (Ed.), Research and reflectivity: 63-75. London: Sage.

Walker, G., Kogut, B., \& Shan, W. 1997. Social capital, structural holes and the formation of an industry network. Organization Science, 8: 109-125.

Watzlawick, P. 1963. A review of the double bind theory. Family Process, 2: 132-153.

Watzlawick, P., Weakland, J., \& Fisch, R. 1974. Change: Principles of problem formation. New York: Norton.

Witt, U. 1997. "Lock-ins" vs. "critical masses"-Industrial change under network externalities. International Journal of Industrial Organization, 15: 753-773.

Jörg Sydow (joerg.sydow@fu-berlin.de) is a professor of management at the School of Business \& Economics, Freie Universität Berlin, and a visting professor at the University of Strathclyde's Graduate School of Business. He received his doctorate from the Freie Universität Berlin. His research focuses on management and organization theory, strategic partnering and interfirm networking, technology and innovation management, project management, and industrial relations.

Georg Schreyögg (schrey@wiwiss.fu-berlin.de) is a professor of organization and leadership at the School of Business \& Economics, Freie Universität Berlin. He received his doctorate from Universität Erlangen-Nürnberg. His current research interests include organizational change, path dependence, and organizational capabilities.

Jochen Koch (jkoch@euv-frankfurt-o.de) is a professor of management and organization at the European University Viadrina, Frankfurt/Oder. He received his doctorate from the Freie Universität Berlin. His research interests include modern and postmodern organization theory, theories of leadership, media management, and the theory of organizational and strategic path dependence. 